\title{
Movimentos subversivos e attentatorios à ordem: uma análise da opinião do Presidente da Província do Paraná a respeito da Greve Geral de 1917, em Curitiba
}

Anne Caroline da Rocha de Moraes ${ }^{1}$

Resumo: Este trabalho tem por objetivo compreender a opinião e o papel expressados pelo Estado com relação à greve operária ocorrida em Curitiba em julho de 1917. Será analisada a Mensagem ao Congresso Legislativo do Estado publicada em Fevereiro de 1918, escrita pelo Presidente do Estado do Paraná Affonso Alves de Camargo. A partir desta fonte e de bibliografia sobre o tema, será abordado no texto um breve panorama contextual a respeito do período, uma abordagem a respeito da formação da classe operária em Curitiba e, por fim, será apontada a sequência de acontecimentos ocorridos durante a greve de 1917 em Curitiba.

Palavras-chave: movimentos sociais, greve, Brasil Republicano, classe operária, Curitiba.

Abstract: This work has for purpose understanding the opinion and the role expressed by the Brazilian State in relation to the working class strike that happened in Curitiba, in July 1917. We will analyze the message to the State Legislative Congress published in February 1918, written by the president of the State of Paraná Affonso Alves de Camargo. Through this source and the bibliography about this theme, a short panorama about context of the period will be approached in the text, as well as the making of the working class in Curitiba and, for last, the sequence of the events occurred during the 1917 strike in Curitiba.

Keywords: social movements, strike, Republican Brazil, Working class, Curitiba.

1 Graduanda em História - licenciatura com bacharelado - pela Universidade Federal do Paraná. 


\section{Introdução}

$O$ anno que vem a findar foi prenhe de acontecimentos que muito impressionaram a opinião publica, disse o então Presidente da Província do Paraná, Affonso Alves de Camargo, fazendo referência ao ano de 1917. E realmente foi um ano conturbado não só para o Paraná, mas para o mundo. A Primeira Guerra Mundial acabava de suscitar nos brasileiros um patriotismo que via na figura do estrangeiro um inimigo iminente. A guerrilha do Contestado dando vitória a Santa Catarina (local de forte imigração alemã) se aliou ao forte antigermanismo dos paranaenses, causando mal-estar dentro do estado. Além disso, ainda a Grande Guerra trazia consequências materiais para os paranaenses: a falta de matéria-prima e de mercados externos trazia principalmente às zonas urbanas forte carestia entre os homens pobres.

É nesse contexto que estoura a greve de 1917 em Curitiba. A partir do Relatório do Presidente da Província do Paraná ${ }^{2}$ referente a este ano, pretendo fazer uma análise sobre sua visão e seus argumentos a respeito deste movimento grevista. A mensagem dirigida ao Congresso Legislativo do Estado apresentada no dia $1^{\circ}$ de Fevereiro de 1918 se trata de um relatório que possui os mais importantes acontecimentos ocorridos na província, na opinião do Presidente. Focando em sua opinião sobre a cidade de Curitiba, visto que era nela

2 Relatório do Presidente da Província do Paraná. Mensagens do governo a Assembléia legislativa. Curitiba, $1^{\circ}$ de Fevereiro de 1918. 
que se encontrava Affonso Alves de Camargo, buscarei compreender os argumentos utilizados pelo presidente, abrangendo-o num panorama mais amplo, através da bibliografia, no qual percebemos que seu relato está intrinsecamente ligado a uma visão elitista das movimentações. Para isso, analisei somente a parte em que o presidente Affonso Alves de Camargo faz referência às greves.

O relatório parlamentar permite enxergar a opinião de um personagem importante, que agiu diretamente nestes movimentos. A força da greve de 1917 na cidade de Curitiba, que nunca havia visto uma greve realmente violenta como esta, com certeza causou mal-estar entre a elite da província, entre eles, seus governantes. Através da leitura do discurso do presidente da província, espero que seja possível traçar uma opinião comum da elite sobre o movimento grevista.

Através da leitura da fonte, busquei separar trechos do discurso que mostravam argumentos chaves da compreensão sobre o movimento e que não estavam claros para minha compreensão, e após uma leitura bibliográfica busquei compreender porque certos argumentos foram utilizados. A leitura de trabalhos historiográficos referentes ao período trouxe à tona elementos que possibilitarão a compreensão do discurso de Camargo. 


\section{Do trabalho escravo ao trabalho livre: a nova lógica capitalista}

No período entre 1890 e 1920 está ocorrendo a consolidação do mercado de trabalho livre ${ }^{3}$, que se trata da desarticulação do sistema de trabalho escravista e sua substituição no país por uma mão-de-obra predominantemente livre. Porém, não pode-se tomar esse movimento como uma mudança evolutiva, visto que entre o trabalho escravo e o que se chamava de trabalho livre havia muitas características em comum. Hall e Stolcke ${ }^{4}$ mostram isso muito bem em seu estudo, e Paiva $^{5}$ recentemente expôs essas similaridades entre os dois tipos de trabalho na Curitiba de meados do século XIX.

Para Sevcenko ${ }^{6}$, a inserção do trabalho livre e a crise da escravidão estão relacionadas à expansão da economia capitalista, mais especificamente a um "segundo momento da industrialização", consequente da Revolução Industrial, que teria levado o modelo capitalista de produção para as mais longínquas paragens do globo. Essa

${ }^{3}$ RIBEIRO, Luiz Carlos. Memória, trabalho e resistência: Curitiba, 1890-1920. Dissertação (Mestrado) - Departamento de História, Universidade de São Paulo, São Paulo, 1985. p. 3.

${ }^{4}$ HALL, Michael M; STOLCKE, Verena. A introdução do trabalho livre nas fazendas de café em São Paulo. Revista Brasileira de História, São Paulo, n. 6, 1983.

${ }^{5}$ PAIVA, João Guilherme de. Trabalho escravo e trabalho livre nos anúncios de jornais em Curitiba no século XIX. Trabalho de Conclusão de Curso (Graduação em História) - Universidade Federal do Paraná, Curitiba, 2013.

${ }^{6}$ SEVCENKO, Nicolau. Introdução. O prelúdio republicano, astúcias da ordem do progresso. In: NOVAIS, Fernando A. (Coord. Geral). História da vida privada no Brasil. Vol. 3: República: da Belle époque à era do rádio. SEVCENKO, Nicolau (Org. do vol.). São Paulo: Companhia das Letras, 1998, p. 7-48.

${ }^{7}$ Idem, p. 8. 
nova economia era marcada por mudanças nos hábitos mais consistentes das sociedades; a partir de 1870, na Europa e EUA, essas transformações ocorrem rapidamente; nesse momento ocorre a criação de grandes complexos industriais onde se reúnem milhares de operários.

No Brasil, o escravo não respondia mais à lógica daquela economia, e a produção cafeeira era a mais apta à nova lógica capitalista. A abolição da escravidão foi finalmente assinada, e havia condições objetivas favoráveis à criação de um projeto estatal de imigração; milhões de italianos, espanhóis, portugueses, etc. vieram para as zonas cafeicultoras suprir a mão de obra. Diferente da Europa e EUA, a economia era mais cafeeira que industrial, mas o café trazia um novo elemento para o país: a modernização. Porém, esta modernização era forçada, visto que não havia como fugir desse processo, que acabou ocorrendo em todo o globo, segundo Sevcenko. O capitalismo expandia seus mercados, suas fábricas (nos EUA e Europa) e suas necessidades de matéria-prima e, cada vez mais, de bens supérfluos. O Paraná não possuía uma economia cafeeira como as principais cidades brasileiras, mas essa economia o afetou de maneira bastante singular.

A desarticulação do sistema escravista acontece muito cedo no Paraná, e até existe um mito de que nunca houve uma sociedade propriamente escravagista neste território. Porém, a escravidão existiu mesmo que em escravarias menores, quando comparadas àquelas de São Paulo ou Nordeste. Em meados do XIX, o mate tornou-se o grande 
responsável pela entrada do Paraná numa economia de mercado livre. O trabalho escravo não era muito ajustável a essa economia, pois ela era sazonal, e manter um escravo nos meses em que não ocorria a colheita era prejudicial. Por isso, desde o início a economia ervateira se utilizou da mão de obra livre.

Assim, “(...) coube à burguesia do mate o reordenamento econômico da sociedade paranaense em torno do trabalho livre e do livre-mercado, com todas as consequências que isso acarretou" $"$; a indústria do mate se concentrava nas cidades, e sua instalação trouxe diversas transformações em todas as relações da sociedade paranaense. Já em fins do século XIX uma população citadina se consolida em Curitiba: eram os burgueses do mate, alguns comerciantes e uma grande gama de homens pobres.

\section{Curitiba deixa de ser provinciana}

Através dos escritos do historiador Rocha Pombo é possível perceber que existe uma vontade de expor Curitiba como um grande centro moderno, porém ele omite a existência de contradições, conflitos e pobreza. Segundo Ribeiro, a partir de 1870 Curitiba começa um

\footnotetext{
8 PEREIRA, Magnus Roberto de Mello. Semeando iras rumo ao progresso: ordenamento jurídico e econômico da Sociedade Paranaense, 1829-1889. Curitiba: Ed da UFPR, 1996. p. 20.
} 
acelerado crescimento demográfico, chegando a dobrar o número da população de 25 mil em 1890 para 50 mil em 1900. O caráter provincial de Curitiba estava ameaçado, pois não podia suportar um crescimento tão acentuado.

Um dos principais motivos para esse aumento de pessoas seria a imigração europeia, já mencionada. Havia uma imigração em massa que respondia à lógica do café paulista, porém no Paraná não se precisava de tanta mão-de-obra para a produção do mate ou pinho. Assim, os imigrantes vinham mais com o caráter de povoamento do que para trabalhar na indústria. Porém essa imigração começa a passar dos limites de absorção pela cidade, e um grande contingente de imigrantes pobres ficam sem trabalho. Começa um processo acelerado de urbanização, mas essa urbanização de Curitiba também estava ligada a um projeto no qual a elite via como progresso a industrialização da cidade. Mas, segundo Ribeiro, a economia ervateira não tinha o caráter expansionista, os homens do mate preferiam investir em mercados mais seguros.

Apesar de certa estagnação, havia na elite um desejo de se tornar fortemente industrial, naqueles moldes do velho mundo. Esse desejo reflete um discurso da inevitabilidade do capitalismo, no qual as desigualdades sociais causadas por ele são naturalizadas. Nesse mesmo período vemos ocorrer a disciplinarização em todas as instâncias da 
sociedade. Segundo Magalhães ${ }^{9}$, no Paraná começa-se a regulamentar o tempo da empresa, que passa a ser o tempo do relógio, e também a corrigir os hábitos da população operária para obter melhor rendimento na produção. Esse novo capitalismo necessitava de uma nova lógica social, e a escola, prisões, casas de correção, etc. serviam exatamente para inculcar essa nova ordem na sociedade.

Segundo Guimarães, essa disciplinarização foi primeiramente financiada pela iniciativa privada, mas logo a responsabilidade seria passada para o Estado, visto que os empresários já não podem dar conta da indisciplina de seus operários. Assim podemos ver claramente um aumento de policiamento nas ruas, e esta polícia não pensava duas vezes em utilizar a violência quando se tratava de manifestações populares; até mesmo chegando a dispersar bailes que aconteciam domingo à noite e atrapalhariam o rendimento do trabalhador no dia seguinte. Interessante perceber que essas práticas se dão, num primeiro momento, não por conta de mobilizações do operariado, e sim por uma espécie de solidariedade dos intelectuais do Paraná para com os empresários europeus.

A polícia passa a ser o "poder explícito"10, afirma Ribeiro, numa sociedade em que já não estava tão claro como antes (relação

\footnotetext{
9 MAGAlHÃES, Marion Brepohl. Paraná: Política e Governo. Curitiba: SEED, 2001.

${ }^{10}$ RIBEIRO, Luiz Carlos. Op. Cit., p. 113..
} 
escravo/senhor) quem tinha a autoridade. Nesse período a polícia passa por um processo de modernização, e ela começa a definir as categorias criminais, falando em nome da civilização da sociedade. Se analisarmos, por exemplo, que falsificadores de documentos, pessoas envolvidas em delitos contra outras pessoas ou propriedade, e agitadores de greve estão incluídos na mesma categoria de "elementos perigosos"11, fica claro que o papel da polícia é de manutenção, através da violência, da ordem capitalista. Desta maneira o Estado liberal se torna autoritário quando vai defender as liberdades individuais.

\section{Trabalhadores paranaenses}

Segundo dados do Censo de 1920, é possível ter uma ideia mínima da ocupação dos trabalhadores na cidade de Curitiba. Segundo as estatísticas, 31,5\% da população paranaense era ativa, e desta, cerca de $27 \%$ trabalhava nos setores secundários ou terciários, ou seja, uma população urbana. O número de indústrias e operários é difícil de definir, visto que no censo de 1920 constam cerca de 623 indústrias ocupando cerca de 7.200 operários, mas com base num relatório do Secretário dos Negócios da Fazenda, Agricultura e Obras Públicas de 1918, o número de indústrias cai para 189, e o de operários para 3.380. Os dados específicos de Curitiba são ainda mais vagos, colocando $70 \%$ da população como ocupada em categorias diversas, sem profissão ou

${ }^{11}$ Idem. 
com profissão não declarada, enquanto $16,08 \%$ está na "transformação e emprego de matéria-prima"12, que seriam os trabalhadores de estabelecimentos industriais. Dentro desse panorama difícil de visualizar, segundo os estudos de Balhana e Westphalen, as principais indústrias eram de erva-mate, madeireira e fundição de ferro. Segundo Ribeiro, apenas duas indústrias ervateiras chegaram a controlar $70 \%$ da exportação paranaense em 1880.

Estes estabelecimentos industriais não se tratavam de grandes complexos industriais com tecnologia avançadíssima que ocupavam milhares de operários: eram geralmente instalações pequenas e precárias. É possível perceber que em Curitiba a primeira greve foi iniciada pela liga dos sapateiros, em 1906. As fábricas de sapatos raramente chegaram a possuir vinte operários, tendo a maioria dois ou três. Através dessa greve podemos perceber elementos que serão muito importantes para compreender a greve de 1917. Na liga dos sapateiros encontravam-se operários vindos da extinta Colônia Cecília, fundada por imigrantes italianos que possuíam forte formação anarquista. Estes buscavam organizar os trabalhadores, porém, a "consciência de classe" era exigência difícil de alcançar entre eles, já que a relação dos patrões com os funcionários era bastante pessoal. Foi durante esta greve que se criou a Fundação Operária Paranaense, que possuía a preocupação de

${ }^{12}$ Idem, p. 130. 
esclarecer os trabalhadores para organizá-los e fortalecer o movimento operário.

O desenvolvimento desta greve demonstra a dificuldade de organizar a classe, e também o uso de táticas para desfazer o movimento; como espalhar boatos para desmobilizar a greve, acusar os colegas de forçarem outros a aderirem, etc. Segundo Ribeiro, a maior dificuldade em mobilizar os operários acontecia porque a relação com os patrões era quase fraternal, e muitos discursos tratavam a relação dos trabalhadores e seus patrões como uma relação que não necessariamente precisava ser de oposição. Mas os anarquistas estavam ali para organizar os trabalhadores e mostrar a eles como conquistar seus direitos e buscar uma sociedade igualitária. O papel dos anarquistas é crucial para as diversas greves que ocorrem durante o ano de 1917.

\section{7: o ano prenhe de acontecimentos}

O ano de 1917 acumulou diversas tensões em Curitiba. Como já foi expresso na introdução, além de todas as consequências que a Primeira Grande Guerra estava acarretando, no Paraná ainda se somava a questão do Contestado. As greves de 1906 haviam levado, em Curitiba, a uma maior organização do trabalhador. Esse trabalhador não era especificamente aquele das indústrias, pois havia muito poucas; o jornal $O$ diário, em 1906, chamava a Fundação Operária Paranaense a 
tomar como operário todo aquele que "luta pela vida, que compra o pão do seu sustento com o suor de sua fronte" ${ }^{13}$. Havia uma tensão nacional, e muitos discursos apelavam para a união patriótica. Enquanto isso, uma imprensa anarquista e socialista está funcionando em Curitiba, e os trabalhadores já estão razoavelmente organizados em sociedades operárias.

$\mathrm{O} 1^{\mathrm{o}}$ de maio daquele ano foi organizado principalmente por anarquistas, que discursaram numa passeata que saiu da Praça Tiradentes; após este ato, ficou decidida a formação de uma Federação Operária de Resistência. Uma violenta greve explodiu em São Paulo, e eram tantos nas ruas que houve um medo geral, pois não havia como controlar a multidão: "As fábricas e oficinas esvaziam-se, enquanto as ruas se povoam de multidões, movimentando-se agitadas em todos os sentidos"14. Em 16 de julho os paulistas saíram da greve, enquanto em Curitiba, através do jornal libertário Terra Livre, ocorre a convocação para um comício em solidariedade aos companheiros de São Paulo. Neste comício se discute a dificuldade que vivem os trabalhadores num momento de crise, em que o mercado internacional está fechado e há um aumento significativo nos preços dos principais alimentos. Após o comício os operários se reuniram e decidiram deflagrar greve, na qual

\footnotetext{
${ }^{13}$ Idem, p. 152.

${ }^{14}$ ESTADO DE SÃO PAULO, apud FAUSTO, Bóris. Trabalho Urbano e Conflito Social. 3. ed. São Paulo: DIFEL, 1983, p. 195.
} 
as principais reivindicações se assemelhavam àquelas paulistas: aumento do salário, diminuição da jornada e alerta sobre a pobreza geral e aumento no custo de vida.

Dia 19 de julho começaram os primeiros piquetes, e os grevistas andavam pela cidade espalhando panfletos e fazendo discursos para convencerem os trabalhadores a aderir ao movimento. A polícia armada acompanhava a movimentação de perto, mas não entrara em nenhum conflito. As lideranças do movimento, segundo Ribeiro, defendiam um movimento pacífico, e a polícia ficara quieta e até ajudara, através de seu chefe Lindolpho Pessoa, nas negociações com os patrões. A luz fora cortada quando milhares de pessoas conseguiram fazer aderir à greve os operários da empresa de eletricidade. Numa tocaia a polícia atira tiros de festim nas massas, que avançam para a polícia e retornam com tiros de pistolas e surras de cacetes.

O cenário é assustador para a população, que não compreende o que acontece. Num primeiro momento se reconhece o direito do operário entrar em greve, enquanto este permanecer em atitude pacífica. Apesar de as lideranças afirmarem que as massas manteriam atitude pacífica, houve tentativas de dinamitar a Associação Comercial do Paraná, a água da cidade fora cortada, saques que impediam fornecimento de alimentos para a cidade, etc. $\mathrm{O}$ chefe de polícia se reuniu com a classe patronal para levar as reivindicações dos operários, mas os patrões diziam que seus empregados não estavam em greve e 
que eles mesmos os haviam dispensado. Após isso, a violência se acirrou e então a maçonaria, segundo Ribeiro, resolveu conversar com os operários e claramente buscar tirar o movimento das ruas, numa busca de restabelecer a ordem. Mas enquanto as lideranças operárias negociavam e a cidade parecia calma, surgem do interior boatos de que todo o sistema ferroviário estaria parado, e de que haviam grevistas em outros locais do estado. Algumas pessoas tentam interditar a ferrovia que ligava Curitiba ao litoral, arrancam fios de telefone, cortam a água da cidade e ocorre até o lançamento de uma bomba em um bonde elétrico.

Diante disso, a polícia resolve separar os "baderneiros" da população trabalhadora. Emite através da imprensa um aviso à "população ordeira" 15 para que ficasse em casa, pois a partir do dia 24 de julho sua ação seria intensificada, devido à violência dos últimos ataques. Finalmente a greve fora sufocada, sendo seus principais personagens presos e deportados.

\section{Mensagem dirigida ao Congresso Legislativo do Estado}

No relatório de Affonso Alves de Camargo a greve está incluída no subtítulo nomeado de ordem pública. O presidente põe neste subtítulo os mais diversos movimentos subversivos e attentatorios à

${ }^{15}$ RIBEIRO, Luiz Carlos. Op cit., p. 179. 
ordem que impressionaram a opinião publica. A partir do relato de Camargo, podemos perceber que o ano de 1917 teve bastante movimentação da força militar, que sufocou pelo menos duas rebeliões: uma liderada por um ex-senador e outra que aconteceu no território chamado de Palmas. Somada a essas movimentações, o presidente inclui a forte gréve de operarios, que se declarou nesta capital [Curitiba] e em outras localidades do Estado.

Segundo descreve Camargo, a greve no Paraná ocorreu por conta das greves acontecidas em São Paulo e também no Rio de Janeiro, e todas teriam as mesmas reivindicações (diminuição das horas de trabalho e aumento do salário). Enquanto permaneceram em attitude pacifica os operários teriam tido apoio geral, inclusive do governo, que teria sido intermediário entre a classe operária e a "classe dos patrões"; além de procurar, através da representação federal, aprovar leis que protegessem os operários, essa classe tão digna de nossos carinhos.

Porém, segundo o presidente, a polícia teve que tomar medidas enérgicas contra alguns elementos estranhos à classe [...] [que] induziram parte dos grevistas a commeter depredações, entre estas o corte da água e luz da capital paranaense. Essa atuação da polícia não teria ocorrido somente em Curitiba, mas em outros locais em que a greve degenerou em anarchia. E para finalizar a parte em que o Presidente relata as greves, ele conta que os operários voltaram a trabalhar, e mesmo assim o governo continuou preocupado com a sórte 
dos mesmos, tendo conseguido melhorias salariais para os setores com salário mais baixo.

Diante deste relato achei bastante interessante perceber a atitude que o presidente tomou diante de tais movimentações. Segundo Ribeiro, o chefe de polícia Lindolpho Pessoa entrou em contato com a presidência do estado a pedido da liderança dos operários, ainda no primeiro dia de greve. Podemos perceber que a atitude do presidente da província condiz com a visão de Lindolpho Pessoa, que vê nas reivindicações dos operários pedidos legítimos.

O relatório demonstra claramente uma afirmação de legitimidade da luta dos trabalhadores enquanto permanecer $o$ pacifismo. Esse discurso, que acreditei ser dissimulado, se mostrou verdadeiro, visto que o chefe de polícia esteve presente em reuniões com a classe patronal para levar-lhes as reivindicações dos operários.

Os patrões, quando afirmam que não existe greve alguma e que aqueles que estão nas ruas são desocupados, causam descontentamento, pois questionam a legitimidade de uma luta que é claramente justa para parte da elite. Então, o relatório de Camargo demonstra uma posição oposta à atitude dos patrões, desconstruindo o que supus a priori: que seu discurso poderia ser generalizado para o restante da elite paranaense.

Mas, longe de concordar com a violência do movimento, o presidente legitima a utilização da violência policial através do 
argumento de que os operários, que estavam pacíficos, foram induzidos a causar depredações e colocar em risco a propriedade dos cidadãos; só neste momento a violência estatal foi utilizada. Neste trecho pode-se perceber que, como afirma Guimarães, a disciplinarização da sociedade passa da mão dos empresários para o Estado, que se utiliza da polícia para alcançar seus objetivos.

Podemos também notar que a classe trabalhadora, que é digna dos carinhos do presidente, só causou danos materiais aos cidadãos porque fora induzida por elementos estranhos à classe. Nesta questão, é importante frisar que o patriotismo estava aflorado por conta do torpedeamento de navios brasileiros por alemães. Segundo o mesmo relatório do presidente, alguns comicios patrioticos degeneraram algumas vezes em manifestações hostis a subditos allemães, mas não somente os alemães sofreram, pois um sentimento contra o estrangeiro se forma. Tanto a Greve como o Contestado ou qualquer movimentação fora do comum era vista como "ação subversiva de inimigos externos" "Além disso, o operário curitibano não sabia utilizar essas ferramentas revolucionárias, eles haviam aprendido com imigrantes, principalmente italianos anarquistas. Nesse contexto fica claro o porquê de o presidente se utilizar de termos como induzida [...] por elementos estranhos à classe, estes seriam os estrangeiros subversivos que induzem o pacífico trabalhador a causar depredações; esse argumento

${ }^{16}$ MAGALHÃES, Marion Brepohl. Op. cit., p. 41. 
encontra grande aceitação entre a população, que torna a repressão da greve um ato heroico e patriótico.

E finalmente, quando o presidente termina sua fala sobre a greve, demonstra que, mesmo após encerrar-se a greve, o governo continuou preocupado com a sorte dos trabalhadores que possuíam menor salário. Essa preocupação demonstra uma crescente necessidade da aceitação de que existe necessidade de se tratar a questão social trabalhista e que a efetividade da aliança entre empresários e polícia poderá acabar-se; os patrões devem perceber que precisam fazer concessões para que não ocorram outros movimentos parecidos e ainda mais violentos.

O relatório do Presidente da Província do Paraná sozinho jamais poderá exteriorizar a complexidade do pensamento da elite paranaense sobre o movimento da greve de 1917, mas acompanhado da análise de uma historiografia sobre o assunto onde se torna possível o cotejamento com outras fontes, vimos que a elite não tinha uma visão homogênea sobre o assunto, muito pelo contrário. Por um lado os empresários negando a existência de greve, do outro os intelectuais, jornalistas e até mesmo o chefe de polícia e o presidente da província apontam para uma efetividade e legitimidade do movimento. A partir de 1917 se torna praticamente impossível para a classe burguesa fechar os olhos e fingir que as movimentações operárias são somente imaginação. 


\section{Bibliografia}

HALL, Michael M.; STOLCKE, Verena. A introdução do trabalho livre nas fazendas de café em São Paulo. Revista Brasileira de História, São Paulo, n. 6, 1983.

MAGAlHÃES, Marion Brepohl. Paraná: Política e Governo. Curitiba: SEED, 2001

PAIVA, João Guilherme de. Trabalho escravo e trabalho livre nos anúncios de jornais em Curitiba no século XIX. Trabalho de Conclusão de Curso (Graduação em História) - Universidade Federal do Paraná, Curitiba, 2013.

PEREIRA, Magnus Roberto de Mello. Semeando iras rumo ao progresso: ordenamento jurídico e econômico da Sociedade Paranaense, 1829-1889. Curitiba: Ed da UFPR, 1996.

RIBEIRO, Luiz Carlos. Memória, trabalho e resistência: Curitiba, 1890-1920. Dissertação (Mestrado) - Departamento de História, Universidade de São Paulo, São Paulo, 1985.

SEVCENKO, Nicolau. Introdução. O prelúdio republicano, astúcias da ordem do progresso. In: NOVAIS, Fernando A. (Coord. Geral). História da vida privada no Brasil. Vol. 3. República: da Belle 
époque à era do rádio. SEVCENKO, Nicolau (Org. do vol.). São Paulo:

Companhia das Letras, 1998. p. 7-48.

Recebido em 08/01/2015, aceito para publicação em 09/05/2016 